\title{
Exploring educator's perceptions of the challenges affecting grade one learners' academic performance in two low socio-economic schools
}

\author{
Aziza Kalam, B Sc OT (UCT), MECl (UP) \\ Lecturer, Department of Occupational Therapy, Faculty of Community and Health Sciences, University of the Western Cape \\ Beth Francke, BSc OT (UWC)** \\ Ayesha Jainodien, BSc OT (UWC)** \\ Jadine Petersen, BSc OT (UWC)** \\ Thembakazi Silo, BSc OT (UWC)** \\ Robyn Turnbull, BSc OT (UWC)**
}

** Students in the Department of Occupational therapy, University of the Western Cape at the time the study was conducted

Introduction: This research study arose out of the perceived poor performance of learners from low socio-economic areas in the Western Cape. To investigate the cause of the poor performance the researchers explored educators' perceptions of some of the challenges that could affect the academic performance of grade one learners.

Method: A qualitative study was used to explore the educators' perceptions. Six grade one educators, from two schools located in a low socio-economic area were selected through purposeful sampling and consented to participate in two focus group discussions. One of these educators dropped out prior to the commencement of the study. The transcribed data were coded, the codes were reduced to categories and from the categories themes were developed.

Findings: Three themes emerged from the data analysis: "Learners can't cope", "Socio-economic environment does play a role" and "The system is still a problem for the child". By using the Person Environment Occupation (PEO) model, to interpret the data; the findings revealed that the educators experienced that the learners' environments as well as their individual characteristics, had a negative impact on the grade one learners' occupational performance in the classroom.

Conclusion: Occupational therapists therefore cannot just offer individual therapy for learners but need to consider their contexts too when planning intervention.

Key words: Academic challenges, curriculum, grade one learners, low socio-economic schools, occupational performance

\section{INTRODUCTION}

One of the major challenges in a democratic South Africa is equalising resources and opportunities; since these were unfairly distributed by the apartheid government (pre 1994)'. Poverty in South Africa is the most visible product of the apartheid regime, as it affects many communities'. At the time of this study, Stats SA', the national poverty levels were reported at $57.2 \%$ in 2006 and $56.8 \%$ in 2009 , with a strong association between increased levels of education and decreased levels of poverty.

According to Olivier, Wood and De Lange ${ }^{2}$, the Western Cape has the lowest proportion of its population (32\%) living below the poverty line in South Africa. However many learners in the Western Cape are still trapped in poverty. Inadequate education is a manifestation of poverty ${ }^{2}$ where there is a poor orientation towards school and learning; low achievement; school backlogs; juvenile crime and violence; physical, sexual and substance abuse; and early school leaving $^{2}$. Schools within low socio-economic communities in South Africa still find it challenging today to cope with the realities of poverty in addition to the critical challenges of transformation in the post-apartheid $\mathrm{era}^{2}$. Some of the challenges that schools in these communities are faced with include lack of resources (material and human), lack of parental involvement, illiterate community members and language difficulties. This decreases the effectiveness of support systems which learners need to excel in their academic performances.

In the Western Cape, isiXhosa, English and Afrikaans are the three languages used as first languages by the overwhelming majority of residents ${ }^{3}$. The Language Policy of Primary Schools of November 2002 (Western Cape Education Department [WCED] circular 2002) ${ }^{4}$ contained two central recommendations: (I) to implement a policy of mother-tongue-based bilingual education in grades $R$ to 6 in all primary schools in the province from 2004/2005; and (2) to institute incentives to guide all children towards electing to take the third official language of the province as their second additional language. The WCED has encouraged parents to enroll their children in mother-tongue education institutions; however, statistics have shown that $26 \%$ of the learners attending English-medium primary schools in the Western Cape did not have English as their home language ${ }^{4}$, they are mostly Afrikaans and isiXhosa first language speakers. Therefore, despite recommendations and efforts from the WCED to promote mother-tongue education, parents chose to enroll their children at primary schools where English is the language of education and learning. The preference is related to the trend amongst non-English speaking South Africans to raise their children as first language English speakers ${ }^{4}$ as English is still commonly regarded as the language of prestige and opportunity. This makes it difficult for their children to cope independently in the classroom. According to Stats $\mathrm{SA}^{5}$, the rate for repeaters in Grade I, in South Africa, averaged at $7 \%$ between 2009 and $20 \mathrm{II}$.

There is little previous research exploring the factors contributing to the high failure rate in grade one learners. Therefore, this study aimed to explore perceptions and experiences of grade 
one educators regarding learners' academic performance in two schools located in low socio-economic areas in the Western Cape. The objectives of this research were therefore to: I) gain an understanding of how the school environment influences occupational performances of grade one learners; 2) explore the reasons for the poor performance of the grade one learners; 3 ) explore the challenges that grade one educators perceived learners to be experiencing with regards to their academic performance, and 4) investigate the need for support for grade one learners experiencing poor academic performance from the perspective of classroom educators. The findings of the study may therefore, be used to improve the learners' basic educational level and to provide support for grade one learners experiencing poor academic performance as well as for their educators.

\section{RESEARCH METHODOLOGY}

A qualitative research method using a qualitative descriptive approach $^{6}$ was used to explore the perceptions and experiences of grade one educators in two schools located within a low socio-economic area in the Western Cape. These two schools were selected and approached as the Department of Occupational Therapy at the University of the Western Cape had a long standing relationship with the schools in question as they had been used for student practical training and for fieldwork visits. A phenomenological approach ${ }^{6}$ assisted the researchers to understand the phenomena from the educators' points of view.

\section{Population and sample selection}

Purposeful sampling ${ }^{7}$ was used in order to select participants for the study because of their specific characteristics, i.e. they were required to be a grade one educator from the two selected schools. After receiving information on the study, six educators volunteered to participate in the study, three from each of the two schools in the Bellville South area of Cape Town, but eventually only five participated in the study.

\section{Data collection}

Two focus discussion groups were conducted with all the participants of the study (one at each school) on two separate occasions. Amongst the 5 student researchers, student researchers I and 2 conducted the first focus group, while the other 3 student researchers took field notes and the second focus group was conducted by student researchers 3 and 4 while the other three student researchers took field notes. There were five participants present in the first focus group and four participants present in the second focus group which was held one week later. One participant missed the second focus group due to illness. The focus groups alternated between the two schools. For the demographic details of the participants see Table $I$.

\section{Table I: Participant demographic details}

\begin{tabular}{|c|c|c|}
\hline Participant & Gender & Years of experience \\
\hline 1 & Female & 29 years \\
\hline 2 & Female & unknown \\
\hline 3 & Female & 10 months \\
\hline 4 & Female & 18 years \\
\hline 5 & Female & 23 years \\
\hline
\end{tabular}

The duration of the groups was between one and two hours. Focus groups were used rather than individual in-depth interviews as they allowed the participants a platform to discuss their perceptions and feelings amongst their peers. Zuckerman-Parker and Shank ${ }^{8}$ suggested that an ideal number for a focus group should be six to eight participants. Open-ended questions were used to stimulate the discussion and to ensure that all topics were covered such as their backgrounds and experience as well as their thoughts
Table II: open ended questions

I. Could you tell us about your experience educating grade one learners?

2. What is the general age of the grade one learners in your classes?

3. What are the academic requirements for grade one learners to pass?

4. Approximately how many learners do you have in your class? - Does this number affect the children's academic performance? (or the way in which you teach?)

- And how does this affect their individual learning?

5. How would you describe the academic challenges within the class?

- How can these challenges be addressed?

6. In your opinion what environmental aspects within the school, home and community, effected the children's learning?

7. Do you think that the language used to teach the children is conducive to learning, how so?

- Do you teach them in their home language?

8. In your opinion what are the learner's personal challenges that they are commonly faced with?

- Why do you think some children do better than others?

9. How involved are the parents of the children at your schools, with the learner's educational performance?

10. What resources are available within the school? - Do you think they are used correctly? - What resources are still needed within the school?

and feelings about the challenges that their grade one learners were experiencing (see Table II).

\section{Data analysis}

The focus groups were audio and video taped for transcription, and field notes ${ }^{8}$ were taken, to note non-verbal cues, by the three researchers who were not directly involved in conducting the focus groups. The data were transcribed verbatim by all five researchers. The data were then analysed through thematic data analysis ${ }^{9}$. The steps followed in order to analyse the data were as follows: coding and then grouping similar codes into categories and then grouping of the categories into patterns or themes 9 .

\section{Trustworthiness}

To ensure trustworthiness ${ }^{6}$, the five student researchers were required to write personal reflective journals to identify any possible biases that they might have had about grade one learners and the learners' challenges. In order to ensure that the data were dependable ${ }^{6}$, the researchers also had external auditors (their university research supervisor) who arranged for peer debriefing after each focus group and who also questioned their interpretation of the data after their coding and thematic analysis. In order to ensure credibility ${ }^{6}$, member checking was also conducted by the researchers with all the participants after the thematic analysis was completed, to ensure that the information was understood correctly by the researchers.

\section{Ethics}

The researchers obtained ethical clearance from the University of the Western Cape to conduct this research. Thereafter, the principals of the two schools were approached and gave permission for the study to be conducted at their schools. After the educators who qualified under the inclusion criteria provided informed consent for participation, the researchers ensured confidentiality by assigning a pseudonym to each participant.

\section{RESULTS}

The information gathered from the five grade one educators who were participants in this study, resulted in three themes (see Table III). 
Table III: Themes and respective categories

\begin{tabular}{|l|l|}
\hline Themes & Categories \\
\hline I "Learners can't cope" & I.I “There's no food" \\
& I.2 Mother tongue \\
& I.3 "Babies in the class" \\
I.4 Learners with special needs \\
& 1.5 "The children don't play anymore" \\
\hline 2 "Socio-economic does & 2.1 Home \\
play a role" & 2.2 School \\
& 2.3 Community \\
\hline 3 "The system is still a & 3.1 "The system is failing us" \\
problem for the child" & 3.2 Role of educators \\
& 3.3 Learners are failing \\
\hline
\end{tabular}

\section{Theme one: "Learners can't cope"}

Theme one relates to the grade one learners' personal attributes that either stemmed from their biological makeup (predisposition to developing learning disorders or special needs) or from their poor home environments. The following categories have emerged from this theme.

\section{"There's no food"}

The participants commented on the behaviour and functional level of the learners in their classrooms due to hunger.

Tiredness, not really concentrating...uhm I mean if you hungry, you can't concentrate, you look but you see in the eyes it's looking but just as looking it's not like ... listening and understanding. (Participant 4)

This quote highlights the strong influence of the low socioeconomic context that the children live in and its impact on their ability to concentrate in the classroom.

\section{"Mother-tongue"}

The participants highlighted that the majority of the learners in the English class were predominantly Afrikaans first language speakers; however their parents enrolled them into English first language classes. They stated that the learners struggled due to the fact that the language of instruction was not the learners' mother-tongue.

Hy's Afrikaans van sy geboorte uur, maar nou gaan hy Engels praat, nou sukkel hy. Hy moet dink in Afrikaans en nou moet hy skryf en dan skryf hy in Engels. Swak uitslae, swak uitslae.... (Participant 2)

(Translation: He is Afrikaans from the day he was born but now he must speak English, now he struggles. He must think in Afrikaans and now he must write in English. Poor results, poor results.)

Participants also mentioned that parents struggled with assisting with their children's homework due to the language barrier and their own lack of basic education.

\section{"Babies in the class"}

One of the participants indicated that the system of the Western Cape Department of Education has failed them; children should be six, turning seven when they enroll for grade one, but the schools however have allowed five year olds to be enrolled in grade one. Due to the socio-economic status of the community most of the parents struggled to pay for grade $\mathrm{R}$ classes and therefore they rather enrolled their children in grade one at an early age as it is less costly.

.... learners must be seven, they must turn seven in grade one...but, but sometimes the system is failing us and saying that we um we can take five and a halves. The parents don't want their child to be in grade $R$ because they don't have the finances to pay for grade $R$ school. So rather take, put them in grade one then, then he is in, in a school. (Participant I)

The number of learners enrolled at a school also had an impact on the number of teachers who are employed, so the school then ended up taking the younger aged children in order to keep the staff establishment of the school. Having learners younger than seven, meant that they were not emotionally mature enough to work independently, thus needing more input from the educators. In addition, they also lacked physical maturity in gross and fine motor co-ordination leading to poor overall performance.

"Learners with special needs"

The participants stated that they had learners with disabilities in their classrooms such as Fetal Alcohol Syndrome (FAS) and Down's syndrome, as well as children with learning disabilities. Having learners with disabilities in a mainstream classroom affected the educators' teaching methods as learners with disabilities require more attention.

So we actually working with a FAS child, and that is a big problem for us in a grade one class. (Participant I)

The teachers reported that prior to 2005, the educators would identify learners with disabilities or developmental delays and refer the learner to the remedial classes, so that the learner would receive individual attention. During the time of the study (20I I), remedial classes were no longer offered at both the schools that were part of this study due to lack of posts.

\section{"The children don't play anymore"}

One of the participants stated that play is a very important learning experience for children and according to the participants the learners don't play like they used to play a few years ago. They further indicated that the learners will rather interact with technological devices, instead of playing outside where they would explore and develop their gross and fine motor skills. Another participant expressed the impact of the social climate of South Africa which is unsafe for children to play outdoors.

the children sit in front of the TV, they playing computer games. Hulle speel nie buitekant. (Participant 4) (Translation: They don't play outside).

These findings link with the third objective of the study which is to explore grade one educator's perceptions of the challenges grade one learners' encounter.

\section{Theme two: "Socio-economic does play a role"}

This theme relates to the learners' environments within their home, school and community. The participants recognised the challenges that the learners encountered within these environments resulting from the low socio-economic status within the area.

\section{"Home"}

The participants strongly felt that the learners' home environments have a big impact on their ability to function optimally within their school environment. Challenges in the home environments included: poverty, overcrowded living conditions within the home, parents' lack of education and lack of parental involvement within the child's schooling career.

... the house they are living in is just a bed or sometimes nothing is there. There's no food for them. (Participant I)

\section{"School"}

One of the participants expressed how the classroom environment affects the learners' ability to engage in the classroom activities. It was found that due to overcrowding in the class, the learner to educator ratio is approximately $50: 1$.

... you must divide yourself between three groups, working at the same time and you must teach groups on the mat. (Participant I)

This high learner to educator ratio prevented the educators from giving each learner the individual attention he/she required.

\section{"Community"}

The participants expressed the importance that socio-economic factors have on the learners' ability to fulfill their academic requirements. 
Factors such as limited resources within the community, high rates of unemployment, high prevalence of gangsterism and use of drugs by community members, high rates of teenage pregnancies and violence were identified as factors that affected the learners negatively.

... the socio-economic environment does play a big role with the type of child that we get, a child that has no resources that the parents don't sit with them. And the parents not there to take the child to the library.... (Participant 4)

... it's the environment plays mainly a role and um the parents, there's also a big gap because the parents are so young um, they are here fifteen, sixteen up to twenty and most of them um experience, has experienced with drugs and, and, and alcohol. (Participant I)

\section{Theme three: "The system is still a problem for the child"}

This theme includes the perceptions the participants had about the protocols, regulations and curriculum expectations set up by the Department of Education. These protocols and regulations originate from the national government offices. The teachers felt that Outcomes Based Education (OBE) and Curriculum 2005 were the cause of the system breakdowns, as the learners were unable to work independently and it required the educators to step in and assist the learners who were experiencing difficulties.

\section{"The system is failing us"}

The participants described their perceptions of the Curriculum 2005 which had replaced the Outcomes-based Education (OBE), in which they experienced numerous pitfalls.

... that is the new system the curriculum 2005. That is the one that really failed us badly. Now you must do it (PE) yourself... and or us, we must concentrate on maths and, literacy.... So you haven't got the time to do that (PE), because your child has to do maths and, and read and write so, that, that is the problem. (Participant I)

The participants explained that subjects such as physical education (PE) and art were taught by the classroom educators, instead of having specialised educators for those subjects. The participants expressed that they did not have the time or knowledge to teach these additional subjects as they were already exceeding their expected roles as classroom educators by providing the learners with extra input for mathematics and reading.

\section{"Role of Educators"}

With the pitfalls of the education system the participants felt they had an obligation to fill in the gaps of the learners' education. They spoke about the large number of learners in the classrooms and the adaptations they made in order to cope with it.

I think you must change your teaching style every time because what works for one, doesn't work for the other. (Participant 3)

\section{"Learners are failing"}

One of the participants felt that the pitfalls of the educational system and the difficulties faced within classrooms have contributed to the high failure rates. Participants estimated that within each class of grade one learners one third of the class failed. Another participant mentioned that she had to fail a lot more children in one year because they simply were not able to fulfill the expectations of the curriculum of grade one.

They can't, they can't make it. Its normally ten or eleven children you can't pass through. (Participant 5)

I failed twenty, twenty-three learners, and that was more than half my class. (Participant I)

\section{DISCUSSION}

The aim of the study was to explore the perceptions and experiences of grade one educators regarding learners' academic performance. In order to conceptualise the research findings, the researchers used the Person Environment Occupation (PEO) model ${ }^{10}$ to assist in understanding the complexities that affect occupational performance of learners at school. The PEO model ${ }^{10}$ best conceptualised the findings from the current study as the model depicts the transactional relationship between the grade one learners (as the person), their environments and their occupations which affects their occupational performance. These three elements (person, environment and occupation) are dynamic and they continue throughout the lifespan of the individual ". As different factors affect each component, it changes the degree of overlap (occupational performance $)^{10}$ between the three components of a person ${ }^{10}$ (individual attributes of each child), environment ${ }^{10}$ (home, school or community) and occupations ${ }^{10}$ (Activities of Daily Living (ADL), play and school work). As the size of the overlap between each sphere increases, the congruency or fit between each component improves and this ultimately leads to the improved occupational performance of that individual ${ }^{10}$.

\section{Factors affecting Occupational Performance}

The typical age of learners in grade one is supposed to be between six to eight years of age which falls in the middle childhood " category of "Industry versus Inferiority". Within this age group, children's main occupations are in the areas of self-care, school and play". Their occupational performance in these areas will be affected by their personal aspects, which consist of their physical, mental and social abilities as well as by the support and encouragement they receive from their caregivers and educators. Under the South African Schools Act of $1996^{12}$, education is compulsory for all South African children from the age of seven (grade one) to age fifteen years, or the completion of grade nine. The findings revealed that the learner age was identified as a challenge since many children are enrolled at school before the required age of seven years. The younger students struggled more with the work as they had not reached the same level of development as a learner of six or seven years of age" .

According to Erik Erikson's stages of development ${ }^{\prime \prime}$ five year olds fall within the preschool development stage and not within the school going stage which could be a contributor to the failure rate. The participants' experienced that learners who have failed often have a decreased self-esteem, as failing demotivates the learners from trying to work hard, whereas their classmates and friends have already progressed to the next grade. The findings further revealed that the low socio-economic status plays a definite role in this aspect as the parents will choose to send their children to primary school rather than crèche or pre-primary school (Grade $\mathrm{R})$, as pre-school fees are more costly.

The findings further revealed that the educators experienced that learners tend to have difficulties in grasping concepts being taught to them when they are hungry. Crepeau et al ${ }^{13}$ stated that in order to facilitate occupational performance, one has to use the physical, cognitive and affective attributes as well as learned and innate skills. It has been identified by the participants of this study, that it is important that the learners have a meal in the morning. This will contribute to improved concentration levels that can in turn contribute to, and increase, their academic performance when school starts. By having a meal in the morning provided by a feeding association ${ }^{14}$, the learners' occupational performances increased because they were then able to concentrate more effectively in the classroom (cognitive) and their physical needs (hunger) had been met.

Language was also identified by the participants as a challenge for some of the grade one learners. The findings showed that the participants perceived that the majority of the children who were in an English first language classes encountered greater challenges since their mother tongue was Afrikaans. According to the participants, people of low socio- economic status in South African communities believe the English language to be a language of opportunities and prestige. The learners who are Afrikaans first language speakers 
and placed in an English first language class need to use all their resources, such as assistance from educators, parents and siblings, in order to learn the English language and meet the requirements of passing to the next grade. The findings indicated that even though it was the parents' preference to have their child in an English class, the parents found it challenging to help their children with their homework as it is in English and they are predominantly Afrikaans speaking and sometimes illiterate.

Learners with disabilities in the grade one classes are often undiagnosed as they have to go through a referral system which is not available. According to the participants, a grade one learner must first fail at least twice within a phase in order to be considered for referral for disability/learning assessment. This is a highly frustrating process because the child is held back for a year, when the child could have been identified earlier, received treatment and progressed on to the next grade. The participants further stated that they did not have enough time to give each learner the individual attention they he/she required. Therefore the learners with learning disabilities would go unnoticed and consequently this hindered them from succeeding in their schooling career. According to the participants, a grade one learner may move on to grade two if he/she can write five sentences at the end of grade one. In order for the grade one learner to progress he/she is required to look at a picture and be able to describe it verbally as well as in in writing.

A finding of this study suggests that the environment from which learners come plays the most influential role on the learners' academic performance. The Person-Environment- Occupation model ${ }^{10}$ assumes that the environment can have an enabling or constraining effect on the occupational performance. The findings showed that educators perceived the environment to have the biggest influence on the learners' academic performance. The findings have shown that many parents do not provide their children with the adequate essential support that grade one learners may require from the home environment.

The findings also revealed that at school, learners are placed in overcrowded classrooms and are not given the individual attention needed at a grade one level. The participants of this study reported that classes accommodate up to 50 learners with only one educator. The learner-educator ratio was not conducive to optimal learning because the educators felt that they could not provide enough individual attention to the learners.

Many challenges were brought up and discussed within the research process including an increase in crime rate, poor socioeconomic conditions and substance abuse in one of the communities in which some of the learners reside. Participants recorded that learners are expected to stay indoors as their safety was at risk. Staying indoors can have the consequence of restricting the learners' physical and social development. The findings suggest that the lack of play could have been a limitation for the learners and could have hampered their gross motor development due to limited opportunities for outdoor play. Play is essential to development as it contributes to the cognitive, physical, social, and emotional well-being of children and youth ${ }^{15}$.

According to the perceptions of the teachers interviewed, unemployment in this community has been a burden amongst community members due to the low level of education of the parents. The lack of resources within the community has been a large concern as it affects the functioning of a community. The findings demonstrated that the children's academic performances were affected by individual factors as well as environmental factors such as overcrowding of classrooms, lack of individual attention, lack of resources, lack of parental involvement and overall poverty within their community.

\section{Implications for Practice}

It is therefore recommended that the Education Department adheres to its criteria for admission to grade one, namely age five turning six by 30 June in the year of admission, as children entering school too early experience challenges regarding school performance. Education for grade one learners needs to be provided in their mother-tongue, and there is the need for access to specialists to assist children with special needs, preferably at their schools. It is recommended that early screening should be done at the community clinics to screen for hearing or developmental delays. In addition to this, parents and especially the teenage parents need to be educated on normal development and basic parenting skills. Low socio-economic communities also need to have access to Early Childhood Development pre-schools that are not as costly as normal pre-schools. Skills training regarding the growing of their own food gardens can also address hunger needs.

Schools need to I) make use of the school clinics assigned to them for help in identifying and assessing the learners that are experiencing difficulties and for referral to the professionals for the provision of relevant services, 2 ) employ qualified physical education (PE) educators to provide the learners with gross motor stimulation, 3 ) reduce the numbers of learners per classroom (i.e. employ more educators), and 4) provide remedial intervention (employ remedial educators or occupational therapists) for the specific needs of the individual learners, thereby optimising their occupational performance in the classroom.

\section{CONCLUSION}

In conclusion, this study has contributed to the understanding of educators' perceptions of the occupational challenges that grade one learners living in low socio-economic communities encounter. The educators were of the belief that the academic challenges grade one learners face are mostly affected by the low socio-economic environmental circumstances from which the learners come. The challenges mentioned were specifically: the lack of resources at school and home, the young age of the learners, second language enrolment as first language, classroom overcrowding and lack of parental involvement.

\section{REFERENCES}

I. Statistics South Africa. Poverty trends in South Africa: An examination of absolute poverty between 2006 and 2011. <http//www.beta2statssa. gov.za>19 October 2014.

2. Olivier T, Wood L, De Lange N. Picturing Hope in the Face of Poverty, as Seen Through the Eyes of Teachers. Cape Town: Juta and Company Ltd; 2009.

3. Olivier M, Anthonissen C, Southwood F. Literacy development of English language learners: the outcomes of an intervention programme in grade $R$. The South African Journal of communication disorders, 2010; 57: 58-65.

4. Western Cape Education Department (WCED) circular 2002. <http: www.wced.pgwc.gov.za/circulars/2003/2002_circulars.xls> 26 November 2014.

5. Stats SA. Millenium Development Goals. <http://www.statssa.gov. za/MDG_Goals2_2013.pdf. > 26 November 2014.

6. Creswell, J.W. Research Design: qualitative, Quantitative and Mixed methods approaches. $4^{\text {th }}$ ed. California: Sage publications; 2014: 20I-203.

7. Patton, M.Q. Qualitative evaluation and research methods. $2^{\text {nd }}$ edition ed. Newbury Park, CA: Sage Publications, 1990.

8. Zuckerman-Parker, M. \& Shank, G. The Town Hall Focus Group: A new format for Qualitative Research Methods. The Qualitative Report, 2008; 13 (4): 630 - 635.

9. Kothari, C.R. Research Methodology: An introduction. New Delhi:New age publishers, 2009.

10. Law M, Cooper B, Strong S, Stewart D, Rigby P \& Letts L. The Person-Environment-Occupation Model: A transactive approach to occupational performance. Canadian J of Occupational Therapy, 1996; 63(I): 9-23.

II. Harder F. The Developmental Stages of Erik Erikson. <http://www. learningplaceonline.com/stages/organize/Erikson.html >; 8 August 2009.

12. South Africa. The South African Schools Act No 84 of 1996. 1996. Retrieved: 16 August 2011. 
13. Crepeau EB, Cohn ES, Boyt Schell BA. Willard \& Spackman's Occupational Therapy (I I Ed). Philadelphia: Lippincott, 2003.

14. Peninsula school feeding association "you can't teach a hungry child". <http://www.psfa.org.za/feeding >; 3 September 201 I.

15. Ginsburg, K. The Importance of Play in Promoting Healthy Child Development and Maintaining Strong Parent-Child Bonds. Pediatrics, 2007: Jan; II9(I): 182-191.

\section{Corresponding Author}

\section{Aziza Kalam}

azizakalam4@gmail.com 